\title{
Overview of the pathogenesis and treatment of chronic inflammatory demyelinating polyneuropathy with intravenous immunoglobulins
}

This article was published in the following Dove Press journal:

Biologics: Targets \& Therapy

5 March 2010

Number of times this article has been viewed

\section{Mohamed Mahdi-Rogers Yusuf A Rajabally}

Neuromuscular Clinic, Department of Neurology, University Hospitals of Leicester, Leicester, UK
Correspondence:Yusuf A Rajabally Neuromuscular Clinic, Department of Neurology, University Hospitals of Leicester, Leicester General Hospital, Leicester LE5 4PW, UK

Tel +44 II 62584576

Fax +44 II6 2584875

Email yusuf.rajabally@uhl-tr.nhs.uk

\begin{abstract}
Chronic inflammatory demyelinating polyneuropathy (CIDP) is an acquired heterogeneous disorder of immune origin affecting the peripheral nerves, causing motor weakness and sensory symptoms and signs. The precise pathophysiology of CIDP remains uncertain although $\mathrm{B}$ and $\mathrm{T}$ cell mechanisms are believed to be implicated. Intravenous immunoglobulins (IVIg) have been shown in a number of trials to be an effective treatment for CIDP. IVIg is thought to exert its immunomodulatory effects by affecting several components of the immune system including B-cells, T-cells, macrophages and complement. This article provides an overview of the pathogenesis of CIDP and of its treatment with IVIg.

Keywords: chronic inflammatory demyelinating polyneuropathy, intravenous immunoglobulin, pathogenesis, treatment
\end{abstract}

\section{Introduction}

Chronic inflammatory demyelinating polyneuropathy (CIDP) is an acquired heterogeneous disorder affecting peripheral nerves caused by a demyelinating process, producing sensory loss and positive sensory symptoms as well as motor weakness. Its prevalence may be as high as 9 per 100,000. ${ }^{1}$ Its reported incidence is variable, with recent analyses suggesting figures between 0.50 and 1.60 per 100,000 per year. ${ }^{1,2}$ In its typical form, the disorder is symmetric and involves both proximal and distal limb regions. There are rarer atypical forms, also known as Lewis-Sumner syndrome, which can produce predominantly uni- or multifocal as well as distal involvement. ${ }^{3}$ Diagnosis relies on clinical features, and also mainly on electrophysiology, which allows demonstration of a demyelinating process, producing slowing of nerve conductions in various segments as well as conduction block. ${ }^{4}$ Cerebrospinal fluid protein level is raised in the majority of cases, and peripheral nerve histology, may be useful in demonstrating a demyelinating process with inflammatory features. ${ }^{4}$ Magnetic resonance imaging (MRI) can show thickened hyperintense nerve roots, trunks or plexi. ${ }^{4}$ As we will see in this article, the pathogenesis of CIDP is inflammatory, most probably autoimmune, involving both $\mathrm{T}$ cells and antibodies. Intravenous immunoglobulins (IVIg) as well as steroids and plasma exchanges have been shown to be effective treatments for CIDP. ${ }^{4}$ The efficacy of IVIg in CIDP has been shown in different randomized controlled trials. ${ }^{4}$

\section{Pathophysiology}

The clinical similarity of chronic inflammatory demyelinating polyneuropathy to GuillainBarré Syndrome, its histologic resemblance to experimental autoimmune neuritis and its response to immunosuppressive therapy, all suggest an autoimmune pathogenesis. 
Experimental autoimmune neuritis can be induced in rodent models by immunization with peripheral nerve myelin or myelin proteins emulsified with Freund's adjuvant. ${ }^{5,6}$ A similar disease can be induced in Lewis rats with purified Protein 2 (P2), Protein 0 (P0) glycoprotein, or Peripheral Myelin Protein 22 (PMP22). ${ }^{7-9}$ The models most studied have been acute, although, some animals develop a chronic relapsing illness with histological appearances resembling CIDP. ${ }^{10-13}$

Currently, neither the target antigen nor the cell population responsible for the pathogenesis of CIDP have been identified. Myelin proteins, mainly P0, P2 and PMP22, have been investigated because of their abilities to induce EAN in animals. ${ }^{9,14}$ Recent studies have focused on P0 because it is the most abundant peripheral nerve myelin protein and can induce EAN. In the study of Yan et al western immunoblot technique identified antibodies to P0 in six of 21 CIDP patients who were responsive to plasma exchange and only in one of 15 controls. ${ }^{15}$ Allen and colleagues also found antibodies to P0-like bands by immunoblot in eight of 32 patients with CIDP and none in 30 normal controls. ${ }^{16}$ However, Sanvito et al did not find a significant difference in the proportion of subjects with IgG anti-P0 peptides in patients with CIDP compared with controls, although individual subjects with CIDP had high titers. In this study there was a higher proportion of untreated CIDP patients compared with healthy controls (4/18 vs 0/32) with IgG antibodies to P2. ${ }^{17}$ The detection of antibodies to $\mathrm{P} 0$ and other myelin protein is likely to be dependent on their conformation, which may only be found on the intact protein in its natural membrane environment. Studies looking for antibodies to gangliosides have been unrewarding in CIDP in contrast to MMN. ${ }^{18}$

Antibodies are not believed to, by themselves, produce demyelination as they are unable to penetrate the blood-nerve barrier unless it is already permeable. There is evidence that a T-cell response is also involved. Systemic and local activation of T-cells has been demonstrated in CIDP ${ }^{19-21}$ and in one study circulating T-cell responses were detected to a $\mathrm{P} 0$ peptide in 3 of 13 cases. ${ }^{22}$ Furthermore, the antibodies to P0 glycoprotein in Yan and colleagues' study were mainly IgG 1, a subclass that implies T-cell activation. ${ }^{15}$ It is likely that both $\mathrm{B}$ and T-cell mechanisms are involved. More research is needed to establish the target of the T-cell response and whether other cell populations, like NK and T-cells are relevant to the pathogenesis of CIDP.

\section{Treatment with intravenous immunoglobulins: rationale, evidence-base and practice}

The treatment of CIDP is based on the notion that the pathogenesis is likely to be immune mediated. The three proven treatments from randomized controlled trials for CIDP are corticosteroids, plasma exchange and intravenous immunoglobulin. ${ }^{23-27}$ Immunosuppresive therapies like methotrexate, azathioprine, cyclophosphamide, cyclosporin A, mycophenolate and alemtuzumab have been used anecdotally. In addition, immunomodulatory agents such as beta interferon have had reports of beneficial effect although a randomized controlled trial failed to confirm this benefit. ${ }^{28,29}$

Intravenous immunoglobulin (IVIg) consists of IgG obtained from the pools of plasma of several thousand healthy blood donors. The mechanism of action of IVIg is complex; it modulates the expression and function of Fc receptors, interferes with the activation of complement and the cytokine network, regulates of cell growth and neutralize of circulating auto-antibodies. ${ }^{30}$ IVIg was first shown to be beneficial in idiopathic thrombocytopenic purpura more than 25 years ago. ${ }^{31}$ Since then, IVIg has been used in a number of autoimmune and inflammatory diseases. Although the presence of natural antibodies capable of recognizing foreign antigens could plausibly explain the role of IVIg in IgG replacement therapy, the precise mechanism of action by which IVIg exerts its immunomodulatory effects is not clearly understood. In inflammatory neuropathies there are several proposed pathophysiological mechanisms. Antiidiotype antibodies are likely to be involved in the therapeutic effects of IVIg and other B-cell mediated effects of IVIg include inhibition of antibody production, ${ }^{32}$ inhibition of B-cell differentiation, ${ }^{33}$ inhibition of production of interleukin- 6 and tumour necrosis factor- $\alpha,{ }^{34}$ induction of B-cell apoptosis, ${ }^{35}$ downregulation of specific auto-reactive B-cells and regulation of $\mathrm{B}$-cell subsets expressing CD5, ${ }^{36}$ thereby suppressing the auto-antibody producing CD20+ B1 cells. IVIg is thought to potentially accelerate the breakdown of endogenous IgG which may be mediating the autoimmune response. ${ }^{37}$ IVIg has also been shown in experimental animals to modulate B-cell migration from bone marrow to secondary lymphoid organs. ${ }^{38}$ In animal models of experimental autoimmune encephalomyelitis and autoimmune uveitis, IVIg is thought to reduce the production of interleukin-2 and interferon- $\gamma$ by T-cells, ${ }^{39,40}$ preventing the development of disease. This is also thought to be one of the major effector mechanisms in the treatment of CIDP. The anti-inflammatory activity of IVIg is at least partly mediated by its ability to prevent the formation of membrane attack complex and subsequent tissue destruction. Antibodies against several components of the classical complement pathway have been identified in IVIg. ${ }^{41-43}$ IVIg-mediated inhibition of macrophage function may furthermore reduce the phagocytosis of antigen-presenting cells and antibody-mediated 
cellular cytotoxicity, thus inhibiting macrophage-mediated demyelination. ${ }^{44}$

In CIDP, Vermeulen et al initially reported treating 17 patients with infusions of fresh-frozen plasma which contains IVIg. There was improvement in 13 patients. ${ }^{45}$ Subsequent open studies of IVIg reported benefit ranging from nine out of nine patients ${ }^{46}$ and 32 of 52 patients, ${ }^{47}$ to 3 of $15 .{ }^{48}$ The first double-blind, randomized, placebo controlled trial was a cross-over of trial of seven patients who were known responders to IVIg; all seven patients improved on IVIg but none improved on placebo. ${ }^{27}$ Another study by the same investigators did not show a difference in response between patients who received IVIg and those on placebo. ${ }^{49}$ These varying results indicated the need for further trials. A randomized, double-blind, placebo-controlled, cross-over trial found a significant improvement in disability scores in 19 of $30(63 \%)$ patients treated with IVIg. ${ }^{25}$ In a large randomized trial of 53 patients ( 30 IVIg vs 23 placebo), 11 in the IVIg group and 2 patients improved in a functional disability scale $(P=0.019) .{ }^{26}$ There have also been trials comparing IVIg with corticosteroids and plasma exchange, the other two proven treatments in CIDP. A randomized, double-blind, crossover trial of 32 patients comparing IVIg with prednisolone (oral prednisolone tapering from $60 \mathrm{mg}$ to $10 \mathrm{mg}$ daily over 6 weeks) showed significant improvement in disability in patients receiving either treatment. ${ }^{50}$ In the cross over trial of IVIg versus plasma exchange, patients were randomized to receive IVIg $(0.4 \mathrm{~g} / \mathrm{kg}$ once a week for 3 weeks, then $0.2 \mathrm{~g} / \mathrm{kg}$ once a week for the next 3 weeks) or plasma exchange twice weekly for 3 weeks then once weekly for another 3 weeks. The study was a unblinded and analysis was not intention to treat, nonetheless there was no difference between the efficacy of IVIg and plasma exchange; both treatments resulting in significant improvement. ${ }^{51}$

Meta-analysis showed significant short-term reduction in disability and improvement in strength with IVIG but there was lack of evidence about the long-term benefit of IVIg. ${ }^{52}$ A recent randomized, double-blind, placebo-controlled, response-conditional crossover trial of 117 patients with CIDP confirmed the long-term use of IVIg. Patients were treated with an initial loading dose of $2 \mathrm{~g} / \mathrm{kg} 10 \%$ caprylate-chromatography purified immune globulin intravenous (IGIV-C), followed by a maintenance dose of $1 \mathrm{~g} / \mathrm{kg}$ every 3 weeks for 24 weeks. After these 24 weeks, only patients who improved during the first study period were re-randomized for an extension phase of another 24 weeks. In first period, 32 of $59(54 \%)$ patients treated with IGIV-C and 12 of 58 $(21 \%)$ patients who received placebo improved in adjusted inflammatory neuropathy cause and treatment (INCAT) disability score $(P=0 \cdot 0002)$. Similar results were obtained in the crossover period. During the extension phase, participants who continued to receive IGIV-C took a longer time before they relapsed (a worsening of adjusted INCAT disability score by 1 point or more from baseline value of the extension) than did patients treated with placebo $(P=0.011) .{ }^{53}$

The standard initiating dose of IVIg for treating CIDP is $2 \mathrm{~g} / \mathrm{kg}$ body weight over 5 days. The effect is short-lived and patients usually require repeated infusions. A retrospective study of 15 patients showed considerable dose and treatment frequency variability, in individual patients. In this study, IVIg dose reductions were achieved in all patients (mean: $63.3 \%$, range: $42.4 \%$ to $88 \%$ ), ${ }^{54}$ raising the question about the need for prospective dose-comparative trials in CIDP, as have been performed in myasthenia gravis. ${ }^{55}$ Recent randomized controlled trials in CIDP have also found that patients did not require as much IVIg as they were receiving. In the RMC trial of methotrexate for CIDP, 14 of $32(44 \%)$ of patients on placebo were able to reduce their IVIg or corticosteroids by more than $20 \% .{ }^{56}$ Similarly, in a study of the efficacy of interferon beta-1a in patients with CIDP, 8 of 17 (47\%) patients in the placebo group who completed the study did not restart IVIg therapy after IVIg was withdrawn. ${ }^{57}$ Intravenous immunoglobulin is expensive; a cost-of-illness study of inflammatory neuropathies showed that the average annual cost per patient for those on IVIg was $£ 17,107$ and those not requiring IVIg, $£ 59$ only. ${ }^{58}$ It is therefore important that clinicians ensure that patients are only given the minimum dose of IVIg they require. However, it remains unclear whether continuous treatment may have long-term favorable effects and maintaining patients on lower doses of IVIg may as a result in further deterioration so that dosing should be directed at maintaining maximal function. ${ }^{59} \mathrm{CIDP}$ patients on IVIg often receive their infusions as in-patients, which adds to the drug costs. Subcutaneous immunoglobulins is an alternative which can be self-administered by patients at home. An observational study of 1500 infusions in primary immunodeficiency diseases showed that patients tolerate it well. ${ }^{60,61}$ There have been few reports of its successful use in CIDP. ${ }^{62,63}$ Controlled studies of subcutaneous immunoglobulins are needed to establish appropriate dose and measure quality of life. An economic study comparing the intravenous and subcutaneous routes is also necessary.

\section{Conclusion}

CIDP is a heterogeneous disorder of complex autoimmune basis which has been found to be treatment responsive in approximately $80 \%$ of cases. ${ }^{64}$ Intravenous immunoglobulins 
represents a safe and effective treatment for CIDP. However, about a third of patients do not respond to IVIg. Furthermore, cost and availability are also major issues that affect its use. The reasons for IVIg unresponsiveness remain unclear although genetic factors may play a role. ${ }^{65}$ Treatment options in such unresponsive remain steroid therapy and plasma exchanges, although these are less well tolerated. Further research may shed light on the important persistent questions regarding long-term use of IVIg for CIDP, and this will require consideration of alternatives as well as, of more adequate and evidence-based use of this highly effective but costly treatment.

\section{Disclosures}

The authors declare no conflicts of interest.

\section{References}

1. Laughlin RS, Dyck PJ, Melton RJ 3rd, Leibson RC, Ransom J, Dyck PJ. Incidence and prevalence of CIDP and the association of diabetes mellitus. Neurology. 2009;73:39-45.

2. Rajabally YA, Simpson BS, Beri S, Bankart J, Gosalakal J. Epidemiologic variability of chronic inflammatory demyelinating polyneuropathy with different diagnostic criteria: study of a UK population. Muscle Nerve. 2009;39:432-438.

3. Rajabally YA, Chavada G. Lewis-Sumner syndrome of pure upper limb onset: diagnostic, prognostic and therapeutic features. Muscle Nerve. 2009;39:206-220

4. Said G. Chronic inflammatory demyelinating polyneuropathy. Neuromuscul Disord. 2006;16:293-303.

5. Waksman BH, Adams RD. A comparative study of experimental allergic neuritis in the rabbit, guinea pig, and mouse. J Neuropathol Exp Neurol. 1956;15:293-334.

6. Lampert PW. Mechanism of demyelination in experimental allergic neuritis. Electron microscopic studies. Lab Invest. 1969;20:127-138.

7. Gabriel CM, Hughes RA, Moore SE, Smith KJ, Walsh FS. Induction of experimental autoimmune neuritis with peripheral myelin protein-22. Brain. 1998;121:1895-1902.

8. Kadlubowski M, Hughes RA. Identification of the neuritogen for experimental allergic neuritis. Nature. 1979;277:140-141.

9. Milner P, Lovelidge CA, Taylor WA, Hughes RA. P0 myelin protein produces experimental allergic neuritis in Lewis rats. J Neurol Sci. 1987;79:275-285

10. Pollard JD, King RH, Thomas PK. Recurrent experimental allergic neuritis. An electron microscope study. J Neurol Sci. 1975;24:365-383.

11. Harvey GK, Pollard JD, Schindhelm K, Antony J. Chronic experimental allergic neuritis. An electrophysiological and histological study in the rabbit. J Neurol Sci. 1987;81:215-225.

12. Brosnan JV, Craggs RI, King RH, Thomas PK. Attempts to suppress experimental allergic neuritis in the rat by pretreatment with antigen. Acta Neuropathol. 1984;64:153-160.

13. Adam AM, Atkinson PF, Hall SM, Hughes RA, Taylor WA. Chronic experimental allergic neuritis in Lewis rats. Neuropathol Appl Neurobiol. 1989;15:249-264.

14. Gabriel CM, Gregson NA, Hughes RA. Anti-PMP22 antibodies in patients with inflammatory neuropathy. $J$ Neuroimmunol. 2000;104:139-46.

15. Yan WX, Archelos JJ, Hartung HP, Pollard JD. P0 protein is a target antigen in chronic inflammatory demyelinating polyradiculoneuropathy. Ann Neurol. 2001;50:286-292.

16. Allen D, Giannopoulos K, Gray I, et al. Antibodies to peripheral nerve myelin proteins in chronic inflammatory demyelinating polyradiculoneuropathy. J Peripher Nerv Syst. 2005;10:174-180.
17. Sanvito L, Makowska A, Mahdi-Rogers M, et al. Humoral and cellular immune responses to myelin protein peptides in chronic inflammatory demyelinating polyradiculoneuropathy1. J Neurol Neurosurg Psychiatry. 2009;80:333-338.

18. Melendez-Vasquez C, Redford J, Choudhary PP, et al. Immunological investigation of chronic inflammatory demyelinating polyradiculoneuropathy. J Neuroimmunol. 1997;73:124-134.

19. Bouchard C, Lacroix C, Plante V, et al. Clinicopathologic findings and prognosis of chronic inflammatory demyelinating polyneuropathy. Neurology. 1999;52:498-503.

20. Khalili-Shirazi A, Gregson NA, Londei M, Summers L, Hughes RA. The distribution of CD1 molecules in inflammatory neuropathy. J Neurol Sci. 1998;158:154-163.

21. Kieseier BC, Dalakas MC, Hartung HP. Immune mechanisms in chronic inflammatory demyelinating neuropathy. Neurology. 2002;59: S7-S12.

22. Khalili-Shirazi A, Hughes RA, Brostoff SW, Linington C, Gregson N. $\mathrm{T}$ cell responses to myelin proteins in Guillain-Barre syndrome. J Neurol Sci. 1992;111:200-203.

23. Dyck PJ, O'Brien PC, Oviatt KF, et al. Prednisone improves chronic inflammatory demyelinating polyradiculoneuropathy more than no treatment. Ann Neurol. 1982;11:136-141.

24. Dyck PJ, Daube J, O'Brien P, et al. Plasma exchange in chronic inflammatory demyelinating polyradiculoneuropathy. $N$ Engl J Med. 1986;314:461-465.

25. Hahn AF, Bolton CF, Pillay N, et al. Plasma-exchange therapy in chronic inflammatory demyelinating polyneuropathy. A double-blind, shamcontrolled, cross-over study. Brain. 1996;119:1055-1066.

26. Mendell JR, Barohn RJ, Freimer ML, et al. Randomized controlled trial of IVIg in untreated chronic inflammatory demyelinating polyradiculoneuropathy. Neurology. 2001;56:445-449.

27. van Doorn PA, Brand A, Strengers PF, Meulstee J, Vermeulen M. Highdose intravenous immunoglobulin treatment in chronic inflammatory demyelinating polyneuropathy: a double-blind, placebo-controlled, crossover study. Neurology. 1990;40:209-212.

28. Choudhary PP, Thompson N, Hughes RA. Improvement following interferon beta in chronic inflammatory demyelinating polyradiculoneuropathy. J Neurol. 1995;242:252-253.

29. Hadden RD, Sharrack B, Bensa S, Soudain SE, Hughes RA. Randomized trial of interferon beta-1a in chronic inflammatory demyelinating polyradiculoneuropathy. Neurology. 1999;53:57-61.

30. Kazatchkine MD, Kaveri SV. Immunomodulation of autoimmune and inflammatory diseases with intravenous immune globulin. $N$ Engl $J$ Med. 2001;345:747-755

31. Imbach P, Barandun S, Baumgartner C, Hirt A, Hofer F, Wagner HP. High-dose intravenous gammaglobulin therapy of refractory, in particular idiopathic thrombocytopenia in childhood. Helv Paediatr Acta. 1981;36:81-86.

32. Kondo N, Kasahara K, Kameyama T, et al. Intravenous immunoglobulins suppress immunoglobulin productions by suppressing $\mathrm{Ca}(2+)$-dependent signal transduction through $\mathrm{Fc}$ gamma receptors in B lymphocytes. Scand J Immunol. 1994;40:37-42.

33. Stohl W, Elliot JE. In vitro inhibition by intravenous immunoglobulin of human T cell-dependent B cell differentiation induced by staphylococcal superantigens. Clin Immunol Immunopathol. 1996:79:122-133.

34. Toungouz M, Denys CH, De Groote D, Dupont E. In vitro inhibition of tumour necrosis factor-alpha and interleukin-6 production by intravenous immunoglobulins. B J Haematol. 1995;89:698-703.

35. Toyoda M, Pao A, Petrosian A, Jordan SC. Pooled human gammaglobulin modulates surface molecule expression and induces apoptosis in human B cells. Am J Transplant. 2003;3:156-166.

36. Vassilev T, Gelin C, Kaveri SV, Zilber MT, Boumsell L, Kazatchkine MD. Antibodies to the CD5 molecule in normal human immunoglobulins for therapeutic use (intravenous immunoglobulins, IVIg). Clin Exp Immunol. 1993;92:369-372.

37. Yu Z, Lennon VA. Mechanism of intravenous immune globulin therapy in antibody-mediated autoimmune diseases. $N$ Eng $\mathrm{J} \mathrm{Med}$. 1999;34:227-228 
38. Sundblad A, Marcos MA, Malanchere E, et al. Observations on the mode of action of normal immunoglobulin at high doses. Immunol Rev. 1994;139:125-158.

39. Pashov A, Kaveri A, Kazatchkine MD, Bellon B. Suppression of experimental autoimmune encephalomyelitis by intravenous immunoglobulin. In: Kazatchkine MD, Morell A, eds. Intravenous Immunoglobulin: Research and Therapy. New York: Parthenon Publishing; 1996:317-318.

40. Saoudi A, Hurez V, de Kozak Y, et al. Human immunoglobulin preparations for intravenous use prevent experimental autoimmune uveoretinitis. Int Immunol. 1993;5:1559-1567.

41. Basta M, Van Goor F, Luccioli S, et al. F(ab)'2-mediated neutralization of C3a and C5a anaphylatoxins: a novel effector function of immunoglobulins. Nat Med. 2003;9:431-438.

42. Frank MM, Basta M, Fries LF. The effects of intravenous immune globulin on complement-dependent immune damage of cells and tissues. Clin Immunol Immunopathol. 1992;62:S82-S86.

43. Mollnes TE, Hogasen K, Hoaas BF, Michaelsen TE, Garred P, Harboe M. Inhibition of complement-mediated red cell lysis by immunoglobulins is dependent on the IG isotype and its $\mathrm{C} 1$ binding properties. Scand J Immunol. 1995;45:449-456.

44. Dalakas MC. Mechanisms of action of IVIg and therapeutic considerations in the treatment of acute and chronic demyelinating neuropathies. Neurology. 2002;59:S13-S21.

45. Vermeulen M, van der Meche FG, Speelman JD, Weber A, Busch HF Plasma and gamma-globulin infusion in chronic inflammatory polyneuropathy. J Neurol Sci. 1985;70:317-326.

46. Faed JM, Day B, Pollock M, Taylor PK, Nukada H, HammondTooke GD. High-dose intravenous human immunoglobulin in chronic inflammatory demyelinating polyneuropathy. Neurology. 1989;39:422-425.

47. van Doorn PA, Vermeulen M, Brand A, Mulder PG, Busch HF. Intravenous immunoglobulin treatment in patients with chronic inflammatory demyelinating polyneuropathy. Clinical and laboratory characteristics associated with improvement. Arch Neurol. 1991;48:217-220.

48. Cornblath DR, Chaudhry V, Griffin JW. Treatment of chronic inflammatory demyelinating polyneuropathy with intravenous immunoglobulin. Ann Neurol. 1991;30:104-106.

49. Vermeulen M, van Doorn PA, Brand A, Strengers PF, Jennekens FG, Busch HF. Intravenous immunoglobulin treatment in patients with chronic inflammatory demyelinating polyneuropathy: a double blind, placebo controlled study. J Neurol Neurosurg Psychiatry. 1993;56:36-39.

50. Hughes R, Bensa S, Willison H, et al. Randomized controlled trial of intravenous immunoglobulin versus oral prednisolone in chronic inflammatory demyelinating polyradiculoneuropathy. Ann Neurol. 2001;50:195-201.

51. Dyck PJ, Litchy WJ, Kratz KM. A plasma exchange versus immune globulin infusion trial in chronic inflammatory demyelinating polyradiculoneuropathy. Ann Neurol. 1994;36:838-845.
52. Eftimov F, Winer JB, Vermeulen M, de HR, van S, I. Intravenous immunoglobulin for chronic inflammatory demyelinating polyradiculoneuropathy. Cochrane Database Syst Rev. 2009;CD001797.

53. Hughes RA, Donofrio P, Bril V. Intravenous immune globulin ( $10 \%$ caprylate-chromatography purified) for the treatment of chronic inflammatory demyelinating polyradiculoneuropathy (ICE study): a randomised placebo-controlled trial. Lancet Neurol. 2008;7:136-144.

54. Rajabally YA, Seow H, Wilson P. Dose of intravenous immunoglobulins in chronic inflammatory demyelinating polyneuropathy. J Peripher Nerv Syst. 2006;11:325-329.

55. Gajdos P, Tranchant C, Clair B, et al. Treatment of myasthenia gravis exacerbations with intravenous immunoglobulin: a randomized doubleblind clinical trial. Arch Neurol. 2005;62:1689-1693.

56. RMC trial. Randomised controlled trial of methotrexate for chronic inflammatory demyelinating polyradiculoneuropathy (RMC trial) a pilot, multicentre study. Lancet Neurol. 2009;8:158-164.

57. Gorson K, Hughes R, Cros D. Efficacy of interferon beta-1a in patients with chronic inflammatory demyelinating polyradiculoneuropathy (CIDP). Neurology. 2008;70(suppl 1):A369.

58. Mahdi-Rogers M, Hughes RAC, McCrone P. Economic costs of chronic inflammatory demyelinating radiculoneuropathy, multifocal motor neuropathy and paraproteinaemic demyelinating neuropathy. J Peripher Nervous Syst. 2009;14(s2):94-95.

59. Vucic S, Black K, Baldassari LE, Siao Tick Chong P, Dawson KT, et al. Long-term effects of intravenous immunoglobulin in CIDP. Clin $\mathrm{Neu}$ rophysiol. 2007;118:1980-1984.

60. Borte M, Bernatowska E, Gardulf A, et al. Efficacy and safety of vivaglobin applied subcutaneously to patients with primary immune deficiency (PID). Interim analysis after more than 1300 Infusions. European Society for Immunodeficiencies (ESID) Weimar. 2002.

61. Ochs HD, Gupta S, Kiessling P, Nicolay U, Berger M. Safety and efficacy of self-administered subcutaneous immunoglobulin in patients with primary immunodeficiency diseases. J Clin Immunol. 2006;26:265-273.

62. Lee DH, Linker RA, Paulus W, Schneider-Gold C, Chan A, Gold R Subcutaneous immunoglobulin infusion: a new therapeutic option in chronic inflammatory demyelinating polyneuropathy. Muscle Nerve. 2008;37:406-409.

63. Koller H, Schroeter M, Feischen H, Hartung HP, Kieseier BC. Subcutaneous self-infusions of immunoglobulins as a potential therapeutic regimen in immune-mediated neuropathies. J Neurol. 2006;253: 1505-1506.

64. Cocito D, Paolasso I, Antonini G, et al. A nationwide retrospective analysis on the effect of immune therapies in patients with chronic demyelinating inflammatory polyradiculoneuropathy. Eur J Neurol. 2009. [Epub ahead of print].

65. Iijima M, Tomita M, Morozumi S, et al. Single nucleotide polymorphism of TAG-1 influences IVIg responsiveness of patients with CIDP. Neurology. 2009;73:1348-1352.
Biologics: Targets \& Therapy

\section{Publish your work in this journal}

Biologics: Targets \& Therapy is an international, peer-reviewed journal focusing on the patho-physiological rationale for and clinical application of Biologic agents in the management of autoimmune diseases, cancers or other pathologies where a molecular target can be identified. This journal is indexed on PubMed Central, CAS,

\section{Dovepress}

EMBase, Scopus and the Elsevier Bibliographic databases. The manuscript management system is completely online and includes a very quick and fair peer-review system, which is all easy to use. Visit http://www.dovepress.com/testimonials.php to read real quotes from published authors. 